\title{
Developing an Art Design Courseware Based on Visual Communication Technology and Computer Aided Instruction Technology
}

\author{
http://dx.doi.org/10.3991/ijet.v10i3.4581 \\ Lixian GUO \\ Heze University, Heze, China
}

\begin{abstract}
Modern teaching has undergone academic reform through information technology. Given the specificity of art design, this field requires the use of multimedia resources and the popularization of teaching courseware. However, the development of teaching courseware remain problematic. The academic research results in this field are still rooted on theories and lack practical significance. This study adopts the perspective of visual communication design technology and combines it with computer-assisted instruction technology to discuss art courseware design making. The teaching courseware is designed with art design history as an example. The experimental tests reveal the effectiveness of the method. Unlike those in a traditional classroom, the learning effects of the proposed method are greatly optimized and promoted. Hence, this method has high application value.
\end{abstract}

Index Terms-visual communication, teaching courseware, Computer Aided Instruction, art design

\section{INTRODUCTION}

Multimedia teaching particularly means that in classroom teaching, teachers inherit rational parts in traditional methods, properly introduce modern techniques and means, and combine the two elements to optimize the transfer and feedback effects of teaching and learning information [1]. Multimedia teaching provides the original stereotyped classroom teaching with the theme of "chalk and blackboard" blend through images and sounds, fully develops students' interests, and activates the classroom climate to adjust students' learning initiatives and to improve learning efficiency. Multimedia teaching is an important research topic in the educational reform process. Under such general background, art design education also encourages a favorable development opportunity. As educational reform deepens, art design education becomes increasingly focused on computer networking technology to generate new changes. In the information era, the art design education method generates new opportunities and irradiates new vitality.

Art design teaching has discipline particularity. Numerous visual materials and dynamic demonstrations are required in a classroom. Multimedia technology can provide excellent support in such cases. Developing teaching courseware with multimedia technology in an art design class can create a vivid and visual teaching environment and consequently overcome the dullness and low efficiency of traditional classroom teaching. As multimedia development software is applied and promoted, a growing number of teachers use and master the software. Teachers start to design and develop multimedia courseware from the perspective of teaching and research. Notably, the design and production of multimedia courseware are influenced by many factors, such as technology and practice effects. During the analysis of the current situation of multimedia courseware making, Gong and Zheng find that the main contents of current educational courseware concentrate on Chinese history and mathematics [2]. The creation of art design courseware has extensive quantity and development requirements. However, most art design colleges remain at the early stages of multimedia courseware design and development, as well as network platform construction. A large gap continues to exist between art design courseware and other disciplines and thus exposes a number of problems. For example, the overall level of courseware making is low and lacks originality. Given that normative methods are not used in courseware making, the making experience is insufficient; that is, courseware logic is unclear, courseware lacks interactive design, and the interface design is dull. Meanwhile, the art design discipline requires highly innovative talents. The traditional art design education mode cannot satisfy the requirements of modern art teaching. Given these reasons, improving the multimedia courseware for art design is imperative. Furthermore, conducting research to combine scientific theoretical knowledge and modern computer technology in the design and development of multimedia courseware for art design, as well as implementing art education reform, is greatly significant.

Multimedia courseware is simply an aided teaching tool. Creators first classify and organize information according to the originalities of the information and then integrate multiple media materials (such as text, image, sound, and animation) in space and time so as to make these materials interactive and consequently create effective multimedia application software products [3]. Many Chinese and overseas studies on multimedia courseware have been conducted. Aziz et al. [4] emphasize the need to design rather than just create multimedia courseware. KucheraMorin summarizes the seven principles of multimedia information design and cognitive theory of multimedia learning [5]. Chinese scholars have also exerted great efforts toward multimedia courseware research. For example, Jin mentions the relationship between color and learning theory and the effects of these two factors on courseware in the publication "Color Design in Multimedia Courseware" [6]. Li starts from aesthetic psychology and combines basic theoretical knowledge of the arts to measure the courseware design necessity from the aesthetic perspective [7]. Zhang combines form and content to 
replace teaching content singleness with formal innovation [8].

In summary, Chinese and overseas research on teaching courseware is mostly focused on the elaboration and richness of the design method and theoretical principle. Practical support and examples are lacking. Research on multimedia courseware is ultimately reflected in the perspective of "making." The present study emphasizes the ways to combine scientific design philosophy and computeraided technology to create high-quality multimedia courseware for art design. This study begins in visual communication design, which is seldom involved in the courseware research field, and combines Computer Aided Instruction (CAI) to introduce the design method for teaching courseware for art design. An example of teaching courseware is then designed, created, verified through a field experiment. Research content and method are rarely explored in relevant literature. Thus, the research content and method presented in this work have great reference value and application prospect.

\section{Visual COMMUNiCATION DESIGN FoR Multimedia COURSEWARE}

Visual communication design is a kind of design that conveys information through visual signs and acts on an individual's vision via graph, text, and color (mainly image). The effect gained from visual perception motivates an individual's psychological reflection to achieve information communication. Information, vision, conveying, and design are core concepts [9]. Visual communication design regards visual information content as the main target and considers information communication effectiveness based on the accurate expression of information content. The application fields of visual communication design involve print publicity products (such as books, magazines, and posters) and publicity media (such as TV, films, and electronic print ads). These applications deliver visual information and perform modeling representative design (which is generally called visual communication design). All these applications are archived through "seeing."

Various expression methods are available for visual communication design. Different expression methods require multiple visual vision elements, including symbol, text, graph, image, digitization, and color.

Students make up the main audience of multimedia courseware. The application of multimedia courseware is aimed at expressing obscure teaching contents that cannot be conveniently explained through language description. Multimedia courseware achieves such expression through appreciable pictures and sounds, which aid in students' acceptance and mastery of teaching contents. In addition, the use of multimedia courseware promotes interactions between teachers and students. The effects of visual communication design for multimedia courseware making are obvious. Through the application of the basic theory of visual communication design, teaching contents and information are fused with various visual elements. The teaching process is completed through visual expression. Visual communication design for multimedia courseware is therefore important. It can boost the effectiveness of information communication and the accuracy of multimedia courseware while enhancing the art of information transfer.
Visual communication design mainly involves four evaluative dimensions: character design, color design, graphic design, and interface layout design. The applications of visual communication design can also be reflected in the aforementioned dimensions [10].

\section{A. Character design}

This study explores character design with emphasis on typeface design and arrangement. Different typefaces can induce diverse feelings. The stroke features and font size of characters are directly related to the feedback on different moods. In terms of stroke features, boldface is upright, foursquare, and powerful; it presents a steady and firm feeling. The imitation Song Dynasty style typeface is slim with slender strokes; it creates positive feelings rooted on dignity and beauty.

Font design also involves another factor, that is, type size. Shui draws such conclusion through research and explains that when a font size exceeds a $0.26^{\circ}$ viewing angle, students at different seat zones in a multimedia classroom can effectively comprehend the text presented on the multimedia courseware. Hence, font design for multimedia courseware is not arbitrary but has certain scientific basis. Generally, setting the font to 18 points in a classroom environment is suitable.

Character arrangement should also comply with reading habits and public ways. Examples include starting from big characters, a horizontal arrangement for the line of sight moving from left to right, and a vertical arrangement for the line of sight moving from top to bottom. Twofold results can be achieved by considering these character arrangement principles, with half of the process centered on rapid and accurate information communication. Characters with proper layout and arrangement can make readers feel conformable, facilitate their understanding, and improve reading efficiency. Character arrangement is a basic requirement of multimedia courseware design.

\section{B. Color design}

TABLE I.

COLOR PSYCHOLOGICAL EFFECT

\begin{tabular}{|c|c|c|}
\hline Color & $\begin{array}{l}\text { Psychological effect } \\
\text { and association }\end{array}$ & Screen output application \\
\hline Red & $\begin{array}{l}\text { Exciting, reminding, } \\
\text { prominent }\end{array}$ & $\begin{array}{l}\text { Vigilance and error, stress } \\
\text { the key point }\end{array}$ \\
\hline Orange & $\begin{array}{l}\text { Exciting, warm, promi- } \\
\text { nent }\end{array}$ & $\begin{array}{l}\text { Vague, difficult to distin- } \\
\text { guish, avoid use }\end{array}$ \\
\hline Yellow & Warning, reminding & $\begin{array}{c}\text { Classification and compari- } \\
\text { son }\end{array}$ \\
\hline Green & Comforting, brisk, quiet & $\begin{array}{l}\text { Foreground color, back- } \\
\text { ground color, main keynote }\end{array}$ \\
\hline Cyan & Straightforward, brisk & Background color \\
\hline Blue & Straightforward, brisk & Background color \\
\hline Brown & Gloomy, quiet & $\begin{array}{l}\text { Vague, difficult to distin- } \\
\text { guish, avoid use }\end{array}$ \\
\hline White & $\begin{array}{l}\text { Straightforward, brisk, } \\
\text { prominent }\end{array}$ & $\begin{array}{l}\text { Background color, promi- } \\
\text { nent character }\end{array}$ \\
\hline Black & Gloomy, heavy & $\begin{array}{c}\text { Background color, general } \\
\text { target }\end{array}$ \\
\hline
\end{tabular}

In visual communication, color often serves as the first visual language because it can attract people's attention and trigger emotional reactions. People's sensitivity to color makes color important in the visual communication design for multimedia courseware. Color psychology indicates different psychological effects brought by colors. 
Color design for multimedia courseware should fully consider courseware contents and key points. The color keynote, layout, and background of each part of a page should rationally match. The color matching principles for multimedia courseware are as follows: colors should be consistent with the theme, content, form and style; keynotes should be unified; comparison should be harmonious; bottom color should be bright; and decoration should be rational and stable to avoid redundancy.

\section{Graphic design}

A graph is an important component of multimedia courseware. It can provide people with the most visual perception and feeling. A picture is better than verbal descriptions because students can accept and understand a picture easily. Graphs in visual communication design can be classified into concrete and abstract graphs. Concrete graphs are beautified and created from concrete natural forms, whereas abstract graphs refer to geometrical graphs, such as dots, lines, and planes. A graph is a language with strong identification and infection. Graphs are easy and convenient to identify and remember, and they can be understood by people with different languages. Moreover, graphs can describe things genuinely and vividly. In multimedia courseware design, the rational application of graphics can stimulate learners' mood, enhance learners' learning interest, and activate the classroom climate.

\section{Interface layout design}

Interface layout refers to the collocation of each page element on the same page and respective positions. In multimedia courseware, interface layout means rationally arranging visual elements (such as character, color, and graph in plane forms) on a page according to the required information contents and expressing rational thinking through visual transfer mode. An excellent courseware page not only expresses teaching intention accurately but also triggers students' interest and induces pleasant feelings. Attention should be paid to several principles of courseware design, including harmony and conciseness.

TABLE II.

LAYOUT SCHEME AND APPLICATION

\begin{tabular}{|c|c|c|}
\hline Type & Layout scheme & Application \\
\hline Square type & $\begin{array}{l}\text { Title on top, copyright } \\
\text { information below, tip } \\
\text { contents on the left and } \\
\text { right, and main part in the } \\
\text { middle. }\end{array}$ & $\begin{array}{l}\text { Home page } \\
\text { or specific } \\
\text { cases }\end{array}$ \\
\hline Corner type & $\begin{array}{l}\text { Title on top, navigation on } \\
\text { the left, wide text on the } \\
\text { right, and auxiliary infor- } \\
\text { mation below. }\end{array}$ & $\begin{array}{l}\text { Text con- } \\
\text { tent }\end{array}$ \\
\hline Title and text type & Title on top, and text below & $\begin{array}{l}\text { Home page } \\
\text { or text } \\
\text { content }\end{array}$ \\
\hline $\begin{array}{l}\text { Left and right frame } \\
\text { type }\end{array}$ & $\begin{array}{l}\text { Title on top, navigation link } \\
\text { on the left, and text on the } \\
\text { right }\end{array}$ & $\begin{array}{l}\text { Catalog or } \\
\text { navigation } \\
\text { page }\end{array}$ \\
\hline $\begin{array}{l}\text { Upper and lower } \\
\text { frame type }\end{array}$ & $\begin{array}{l}\text { It is similar to left and right } \\
\text { frame type, but it is divided } \\
\text { into two pages up and down. }\end{array}$ & $\begin{array}{l}\text { Text con- } \\
\text { tent }\end{array}$ \\
\hline $\begin{array}{l}\text { Comprehensive } \\
\text { frame type }\end{array}$ & $\begin{array}{l}\text { It is similar to corner type, } \\
\text { but frame structure is used. }\end{array}$ & $\begin{array}{l}\text { Text con- } \\
\text { tent }\end{array}$ \\
\hline
\end{tabular}

Generally, there are varieties of layout forms, including square type, corner type, title and text type, left and right frame type, upper and lower frame type and comprehensive frame type. Left and right frame type is used most commonly. Table 2 shows various layout schemes and their common application.

\section{Visual COMMUNICATION DESIGN For Multimedia COURSEWARE}

Courseware design is a significant link between courseware development and making and vividly presents courseware before its completion. Courseware design requires a combination of pedagogy and psychology and is conducted in accordance with course teaching objective, teaching content, and objects. For example, art design history is used in this study to design and make multimedia courseware. Courseware design that is oriented to visual communication technology should consider system structure, interface design, and interaction design.

\section{A. System structure}

The system structure of multimedia courseware comes in three kinds: linear, tree, and net. Courseware can be divided into different modules according to contents. Courseware contains multiple knowledge points in the form of pagination. Each page is mutually linked with knowledge points. The system structure of art design history in this study is divided into five modules: course navigation, teaching content, classroom discussion, knowledge review, and other modules (such as assignment arrangement, course preview, and reference). System structure refers to the fundamentals of layout design in visual communication design and is designed according to blocks so that visual presentation is clear.

\section{B. Interface design}

Interface design generally refers to layout, color matching, and font designs. Interface design is the overall manifestation pattern of pages in the courseware. Combining the balance, consistency, and conciseness principles of visual communication design and application dimension, we apply the most classical interface layout to create a low-fidelity courseware prototype design (Figure 1).

The main course module area contains teaching content and classroom discussion, and the after-class assignment search module is set on the homepage for convenient lesson search. Chapter catalog is presented in the navigation panel on the left. When a chapter is clicked, the list of courses appears on the right. The learning interface of each course can be accessed by clicking. Regarding course learning interface, this study applies visual communication for detailed design and combines characters, graphs, and animations. Meanwhile, an exciting and attractive orange color is applied for the title. Interface design is the most important part of courseware design (see Figure 1).

\section{Interaction design}

Interaction design is relatively concise and is dominated by page clicking. The title on each page can be clicked to return to the homepage on each page. When you click the name of any module, you can jump to that module. Pages are turned by advancing and retreating. Moreover, the course progress bar is set below as a reminder of the learning schedule. This bar is humanized and effectively complies with the concise design principle of visual communication (see Figure 2). 
PAPER

Developing AN ARt Design COURSEWARE BASEd on Visual COMMUniCATION TeChNOLOGY AND COMPUTER...

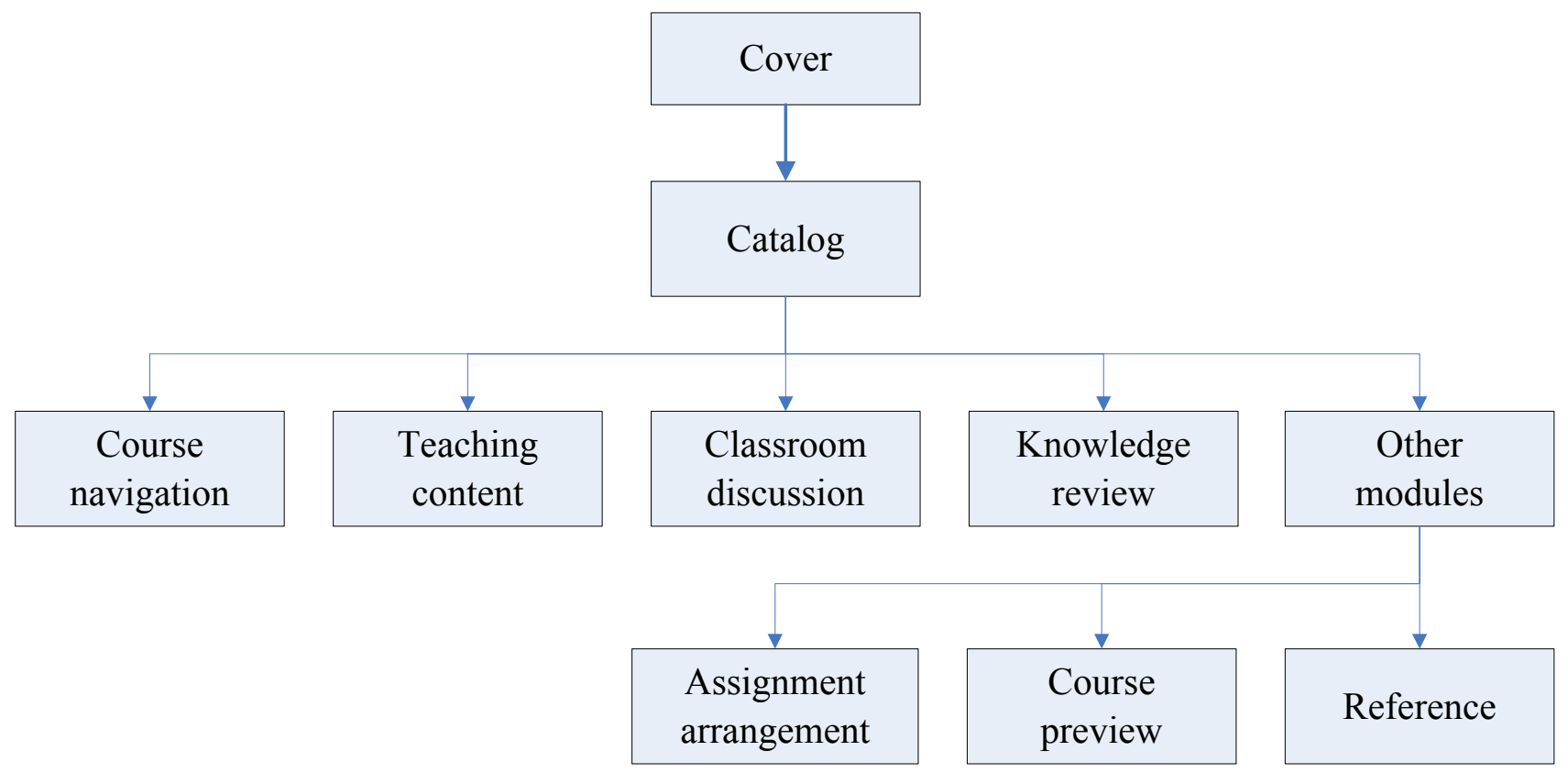

Figure 1. Tree diagram of courseware structure

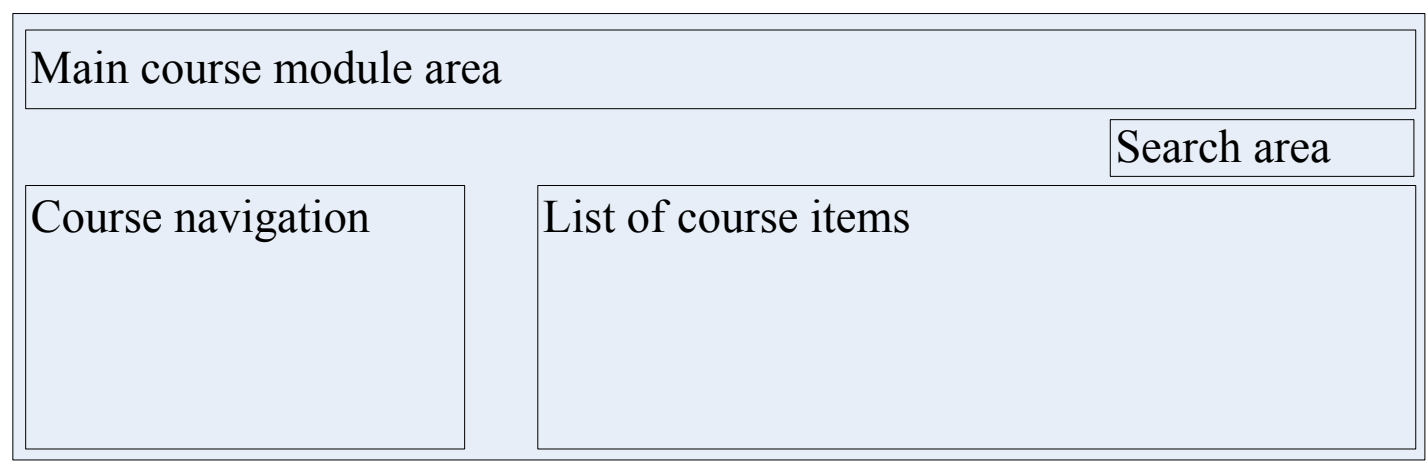

Figure 2. Low-fidelity prototype of the interface

\section{COURSEWARE DEVELOPMENT}

Courseware making mainly includes theoretical technical preparation, resource collection, making, synthesis, and testing etc. CAI plays a great role in optimizing classroom teaching. Specifically, the CAI courseware-making process can be explained through the following flow chart.

In courseware making, we generally begin by selecting a topic, specifying the course teaching objective, combining the teaching contents and teaching program, and considering the features of the audience. During courseware design, we should follow the basic principles and general laws of teaching, refer to classroom teaching experience, and design teaching links that match the courseware [11]. General teaching is "putting problems-analyzing problems-solving problems-conclusions." Hence, the same mode could be adopted in courseware design. The next two steps are important: collecting courseware materials and selecting the tools for courseware making. Courseware materials include common characters, graphs, and videos. In addition, animation and decoration can be added to adjust the classroom climate. Diversified visual communication can double the teaching effects. Courseware-making tools come in many varieties. In terms of material contents, courseware making is divided into text making, picture processing, animation production, and voice frequency editing. The corresponding software programs include Word, PS, Flash, and 3ds Max. Multiple materials are made into other materials with these tools. These materials are integrated and edited using multimedia-making tools. Synthesis tools include Authorware and Founder Author. These tools are easy and convenient to operate. Multiple materials can form chapter catalog structures as required. Rich interaction modes and applications can be set for linkage. These tools are easy to use and are useful for courseware making.

In terms of material treatment, this courseware comprehensively applies Word, PS, and Fireworks for image-text treatment and uses Cooled it for sound effect treatment. Finally, Authorware is used to complete synthesis. The courseware made for art design is shown in Figure 4. Aside from a courseware content module, this courseware contains classroom discussion and assignment arrangement modules. As for interface design, relevant theoretical knowledge of visual communication technology is applied to achieve a rational visual presentation layout and prominent key points. This design can effectively improve student interest. (see Figure 3) 


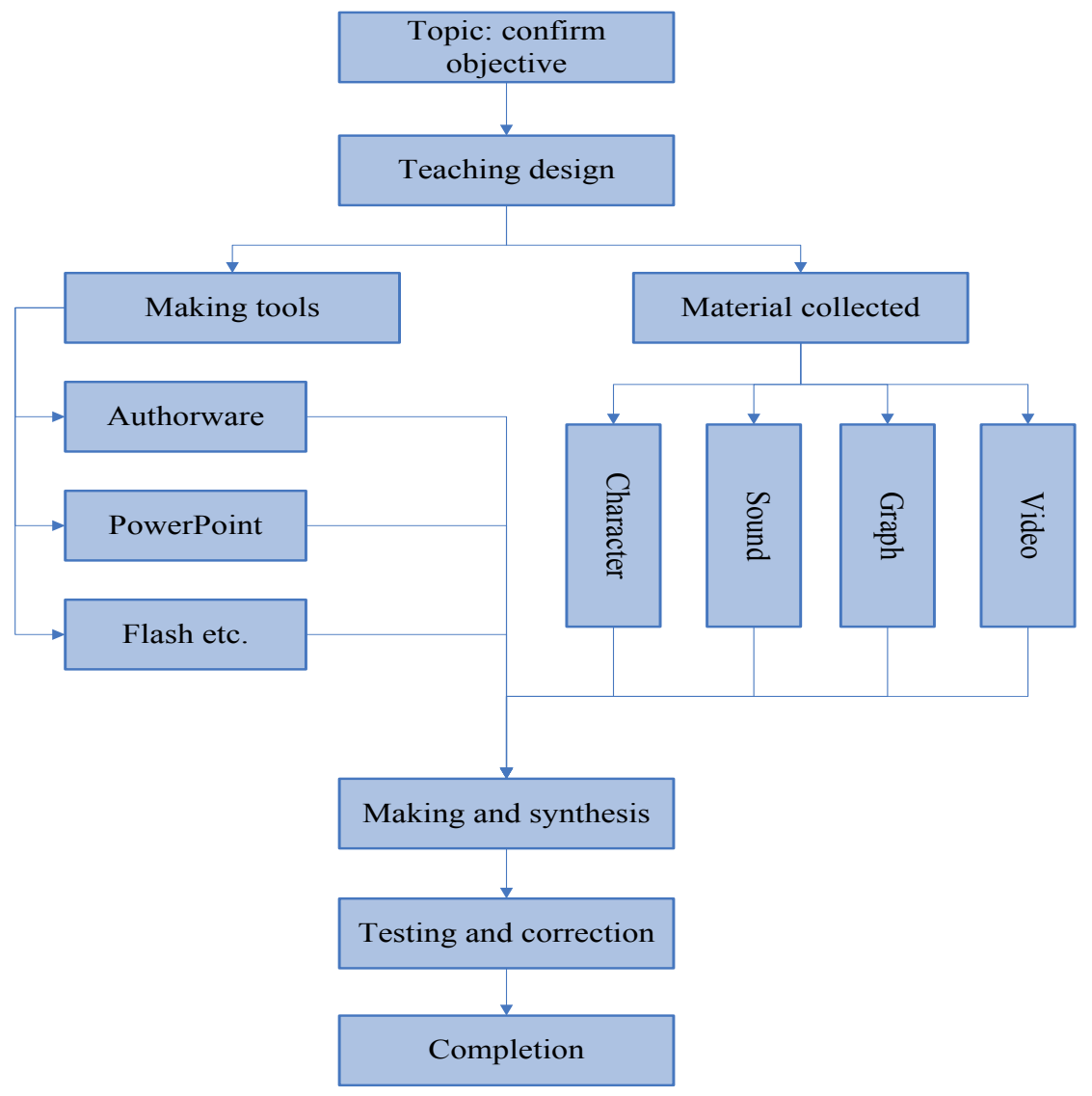

Figure 3. Flow chart of courseware making

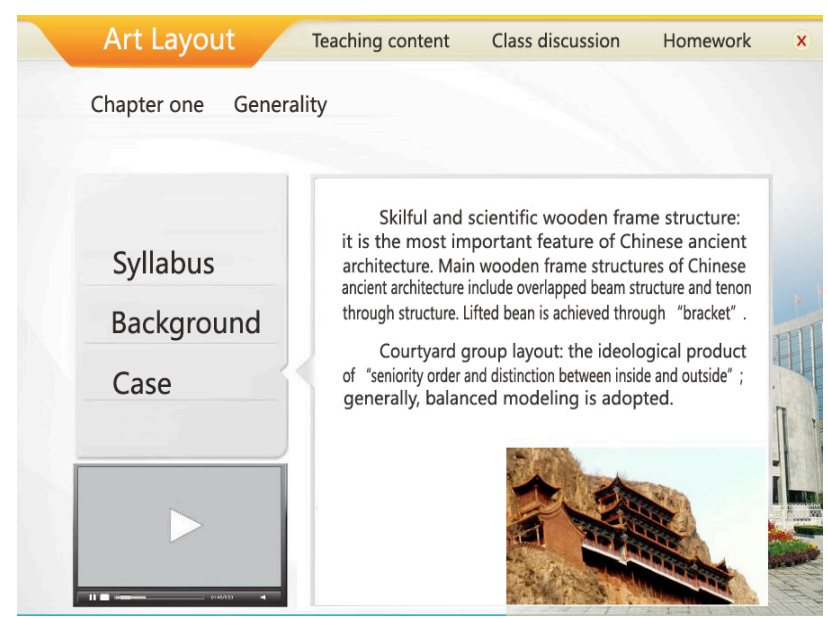

Figure 4. High-fidelity prototype of interface

\section{COURSEWARE DEVELOPMENT}

To verify the effectiveness of the multimedia courseware, 150 freshmen (64 males and 86 females) in an art college were selected randomly as experimental samples in this study. Moreover, 71 students served as the experiment group while 79 students served as the control group. The students in the experiment group learned art design history through the multimedia courseware while the students in the control group received traditional classroom learning. The learning duration was two class hours. The same teacher was appointed to each group.

In this experiment, the learning effects of the multimedia courseware were evaluated from three dimensions: 1) test performance, 2) teacher evaluation of students' classroom performance, and 3) students' questionnaire survey.

After classroom learning, the tests were collected and scored by the teacher. Meanwhile, questionnaires were distributed to the students (135 questionnaires were distributed and 124 questionnaires were collected; 110 questionnaires were effective, including 50 in the experiment group and 60 in the control group). The first two dimensions were of a centesimal system while the third dimension was of a five-mark system. The overall experimental results are shown in the following table.

TABLE III

OVERALL EXPERIMENTAL RESULTS

\begin{tabular}{cccc}
\hline Group & Dimension 1 & Dimension 2 & Dimension 3 \\
\hline $\begin{array}{c}\text { Experiment } \\
\text { group }\end{array}$ & 85 & 90 & 4.2 \\
Control group & 78 & 80 & 2.7 \\
\hline
\end{tabular}

As shown in the table, the performance of the experiment group on the three dimensions was superior to the effects of traditional classroom teaching. In classroom testing, the classroom average score of the experiment group was 6 points higher than that of the control group. During the teacher's evaluation, the students' class participation and the number of questions asked by the students in class were considered. The score of the experiment group was as high as 90 . In the questionnaire, the difference was increasingly obvious, as shown in the following table. 
PAPER

Developing AN ARt Design COURSEWARE BASEd on Visual COMMUniCATION TeChNOLOGY AND COMPUTER...

TABLE IV.

QUESTIONNAIRE SURVEY RESULTS

\begin{tabular}{|c|c|c|c|c|c|}
\hline Group & Number of students & Classroom climate & Teacher's satisfaction & Learning effect & Overall evaluation \\
\hline Experiment group & 50 & 4.4 & 4.0 & 4.1 & 4.2 \\
\hline Control group & 60 & 2.5 & 3 & 2.3 & 2.7 \\
\hline
\end{tabular}

In terms of the classroom climate and learning effect, the scores of the experiment group were almost twice those of the control group. This result fully explains the significance of an effective multimedia courseware in an art design course, especially with regard to activating classroom climate and improving students' learning effects. Teaching courseware based on visual communication and CAI is considerably superior to traditional classroom education.

\section{COURSEWARE DEVELOPMENT}

The rapid development of computer networking technology has allowed such innovation to permeate traditional classroom education. In the research field of art design courseware, research that begins from visual communication and combines technology with CAI is still few. Hence, systematical scientific theory support and cases are lacking. This study combines multidisciplinary visual communication design and computer-aided skills to discuss the design and production of art design courseware. The production practice and control experiment for the teaching of art design history through the courseware and through the traditional method verify the feasibility and effectiveness of the courseware and its design methods. This study also provides new basis and research inspiration for art courseware research. We hope that the combination of the visual communication design of visual aesthetics and CAI in this study can generate positive results for teachers and the users of the multimedia courseware, improve daily teaching levels, and help many students.

\section{REFERENCES}

[1] Yuan Qin, "Study on visual communication design in multimedia courseware". Chengdu: Southwest University, 2010.
[2] Gong Yan, Zheng Xiaojun, "Analysis of research status of multimedia courseware design and making." China Education Information, vol.15, no.2, pp.60-63, February 2014

[3] Zhang Leilei, "Visual design and making of art teaching multimedia courseware." Journal of Educational Institute of Jilin Province (Discipline Version), vol.28, no.2, pp.65-66, February 2012

[4] Aziz N, Mutalib A A, Sarif S M, "Critical analysis in proposing a conceptual design model of assistive courseware for low vision (AC4LV) learners." International Journal of Computer Applications, vol.92, no.10, pp.18-25, October 2014 http://dx.doi.org/10.5120/16044-5173

[5] Kuchera-Morin J A, Wright M, Wakefield G, et al, "Immersive full-surround multi-user system design." Computers \& Graphics, vol.40, no.6, pp.10-21, June 2014. http://dx.doi.org/10.1016/ j.cag.2013.12.004

[6] Jin Yan, "Color design in multimedia courseware." Journal of Fujian Institute of Education, vol.16, no.4, pp.114-117, April 2005.

[7] Li Hongxia, "Study on aesthetics of multimedia courseware making." Inner Mongolia Normal University, 2007.

[8] Zhang Qingmei, "Introspection and reconstruction of college multimedia courseware teaching." Modern Distance Education, vol.27, no.3, pp.60-62, March 2008

[9] Zhengfang FU, Hong ZHU, "A multi-resolution image fusion algorithm based on multi-factor weights." Journal of Digital Information Management, vol.12, no.5, pp. 303-310. October 2014.

[10] Shui Rende, Wang Lidan, "Effects of font size and presentation position on character comprehension of multimedia courseware." Applied Psychology, vol.14, no.2, pp.187-192, February 2009.

[11] Ni Wei, Wu Renchang, "The key steps of CAJ courseware making." Education Science \& Culture Magazine, vol.26, no.08X, pp.53-53, August 2007.

\section{AUTHOR}

Lixian GUO is an associate professor in School of Architecture, Heze University, Heze, 274015, China. Her research interests include Art Design and Visual Communication (guolixian1@yeah.net)

Submitted 23 March 2015. Published as resubmitted by the author 11 May 2015. 